“Assessing Novices' Game Performance in Rugby Union: The Rugby Attack Assessment Instrument (RAAI)"

by Llobet-Martí B, López-Ros V, Barrera-Gómez J, Joel Comino-Ruiz J

Journal of Teaching in Physical Education

(C) 2016 Human Kinetics, Inc.

Note. This article will be published in a forthcoming issue of the Journal of Teaching in Physical Education. The article appears here in its accepted, peer-reviewed form, as it was provided by the submitting author. It has not been copyedited, proofread, or formatted by the publisher.

Article Title: Assessing Novices' Game Performance in Rugby Union: The Rugby Attack Assessment Instrument (RAAI)

Authors: Bernat Llobet-Martí1 ${ }^{1}$, Victor López-Ros ${ }^{2}$, Jose Barrera-Gómez ${ }^{3}$, and Joel CominoRuiz $^{2}$

Affiliations: ${ }^{1}$ Department of Sports Sciences; ${ }^{2}$ Faculty of Psychology and Education; University of Girona, Girona, Spain. ${ }^{3}$ Departament de Matemàtiques, Universitat Autònoma de Barcelona, Bellaterra, Spain.

Journal: Journal of Teaching in Physical Education

Acceptance Date: June 5, 2015

(C)2016 Human Kinetics, Inc.

DOI: http://dx.doi.org/10.1123/jtpe.2014-0134 
“Assessing Novices' Game Performance in Rugby Union: The Rugby Attack Assessment Instrument (RAAI)”

by Llobet-Martí B, López-Ros V, Barrera-Gómez J, Joel Comino-Ruiz J

Journal of Teaching in Physical Education

(C) 2016 Human Kinetics, Inc.

\begin{abstract}
The application of Teaching Games for Understanding (TGfU) and Game Centered Approaches (GCA) in team sports initiation generated the need for assessing game performance. In this paper we introduce the Rugby Attack Assessment Instrument (RAAI), a tool to assess the actions of players in attack and their incidence in the generated game situations in rugby. The RAAI focuses the attention on the ball carrier during a 5 vs. 5 situation. The actions of players in possession of the ball are described and codified. A weight is allocated to each simple and combined action in relation to its tactical value. Thus, the codified actions provide a weighted Index of Performance, the team score of the RAAI. Validity and reliability were tested in two different studies. Results suggest that the RAAI is valid and reliable to assess ball carrier's actions and their influence in attacking game situations of novice rugby union players.
\end{abstract}

Keywords: evaluation, tactical action, team performance, game centered approaches, rugby union. 
“Assessing Novices' Game Performance in Rugby Union: The Rugby Attack Assessment Instrument (RAAI)” by Llobet-Martí B, López-Ros V, Barrera-Gómez J, Joel Comino-Ruiz J

Journal of Teaching in Physical Education

(C) 2016 Human Kinetics, Inc.

In recent decades, as game-centered approaches have emerged, the teaching and learning of team sports has undergone substantial changes. The works of Mahlo (1974) and Deleplace (1979) had an important influence in this respect, challenging the dominant technique led-approach, and stating the need for teaching team sports in their context through game situations. In a similar vein, Bunker and Thorpe (1982) created the Teaching Games for Understanding (TGfU) as a model of teaching sports starting from tactics, reviewed later by different authors (i.e. Kirk and MacPhail, 2002). In other scenarios, new game-centered approaches appeared, such as Game Sense (den Duyn, 1997), the Tactical Games Model (Griffin, Oslin, \& Mitchell, 1997), the Tactical-Decision Learning Model (Gréhaigne, Wallian, \& Godbout, 2005) and the Invasion Games Competence Model (Farias, Mesquita \& Hastie, 2015), among others. These game centered approaches have been tested in different teaching and learning situations of invasion team sports (Miller, 2015).

These approaches require the use of new assessment tools focused on tactical skills. Two assessment instruments fulfilled this need: the Game Performance Assessment Instrument (GPAI) and the Team Sport Assessment Procedure (TSAP) (Oslin, Mitchell, \& Griffin, 1998; and Gréhaigne, Godbout, \& Bouthier, 1997; respectively). Their main contribution was the assessment of tactical behaviors of learners. These instruments make sense in the framework of a constructivist perspective as the teaching and learning process is contextualized and based on developing the skills that emerge from game situations. Arias and Castejón (2012), and Arias-Estereo and Castejón (2014) present an extensive review of the assessment tools used in physical education (PE), extra-curricular sports, and research, concluding that GPAI has been the most frequently applied assessment tool.

The GPAI centers the observation on seven game components: base, adjust, decisions made, skill execution, support, cover and guard/mark. The coding system is based on observing the appropriateness or efficiency of players' actions for each of the game 
“Assessing Novices' Game Performance in Rugby Union: The Rugby Attack Assessment Instrument (RAAI)”

by Llobet-Martí B, López-Ros V, Barrera-Gómez J, Joel Comino-Ruiz J

Journal of Teaching in Physical Education

(C) 2016 Human Kinetics, Inc.

components. Two scores are calculated, Game Performance (GP) and the Game Involvement (GI). Memmert and Harvey (2008) described five limitations of this instrument, namely, the calculation indices, the game performance analysis using involvement versus performance indexes, observer reliability, nonlinearity and usefulness of action. GPAI has also been reviewed and used in relation to the game performance behaviors. Harvey, Cushion, Wegis and Massa-González (2010) tested the appropriateness of GPAI defensive aspects in soccer with positive results. Research on net games has also used GPAI in tennis (Casey \& Dyson, 2009) and volleyball (Hopper, 2003), among others.

The TSAP bases its observation on the actions of the ball carrier and the players' capacity to conquer the ball as a defensive action. Gaining possession of the ball and disposing the ball are the two criteria of six observational variables that reflect the global offensive performance of students during small-sided games (Gréhaigne et al., 1997; Gréhaigne, Richard et al., 2005). Three scores are produced: volume of play, efficiency index, and performance score. The efficiency index is related to those successful actions that have a tactical value to score or to conquer the ball. Some studies have suggested modifications of TSAP to adapt it to different contexts and sports (e.g. Nadeau, Richard, and Godbout, 2008; ice hockey). In addition, Arias and Castejón (2012), and Arias-Estero and Castejón (2014) reviewed its application in research involving the assessment of team sports performance.

Recently, other assessment tools of game performance have been introduced to authentically assess game play performance. These include Game-test situations (GTS) (Memmert, 2007) and the Basketball Offensive Game Performance Instrument (BOGPI) (Chen, Hendricks, \& Zhu, 2013).

The core of our study is the assessment of team performance in attack in rugby union. Only a few studies assess some aspects related to decision-making in rugby (e.g. Gabett, 
“Assessing Novices' Game Performance in Rugby Union: The Rugby Attack Assessment Instrument (RAAI)”

by Llobet-Martí B, López-Ros V, Barrera-Gómez J, Joel Comino-Ruiz J

Journal of Teaching in Physical Education

(C) 2016 Human Kinetics, Inc.

Wake, \& Abernethy, 2011), but none of them analyze the effect of individual behaviors of player on team performance. The aim of this paper is to introduce the Rugby Attack Assessment Instrument (RAAI). This tool was designed in the context of rugby initiation with the objective of assessing the actions of the ball carrier and their influence in the development of a 5 vs. 5 game in attack, producing a team score as a result of cooperative behaviors of players. The specific objectives of this work were: (1) to establish content validity of the instrument, (2) to test construct validity of the RAAI, and (3) to determine the reliability of the RAAI. We focus the analysis on the ball carrier's actions because we consider that the decisions made around the ball are led by collective actions of players in pursuit of the main objective of the game following the principles of support and continuity (Villepreux, Brochard, \& Jeandroz, 2007). Moreover, the offside rule in rugby limits the positioning of players behind the ball centering the game on the ball carrier. We have designed the RAAI to be applied in research that analyses a live teaching and learning sequence of tactical competences of novice rugby players. The present assessment tool provides a team score that represents the sum of the actions of the players within a team.

\section{Basis and development of the RAAI}

The RAAI is a video-based instrument of assessment carried out during the filming of a small-sided game of 5 vs. 5 during 10 minutes. The field dimensions are 30 meters wide and 45 meters long. The main rules are: (a) kicking is not allowed; (b) there are no scrums or line outs; (c) the game is restarted tapping the ball with one foot and passing it, being the defenders five meters away. The rest of the rules are the same as rugby union (Biscombe $\&$ Drewett, 1998). To record the game, two video cameras were fixed at both ends of the field. 
“Assessing Novices' Game Performance in Rugby Union: The Rugby Attack Assessment Instrument (RAAI)”

by Llobet-Martí B, López-Ros V, Barrera-Gómez J, Joel Comino-Ruiz J

Journal of Teaching in Physical Education

(C) 2016 Human Kinetics, Inc.

\section{Units of analysis}

The basic unit of analysis is the action of the ball carrier. All possible attacking actions of this player were previously identified and categorized in accordance with the work that takes into account the game actions, and the action rules in relation to the principles of the game in movement (Gréhaigne, Richard et al., 2005; Villepreux et al., 2007). We carried out this identification filming 5 vs. 5 game situations with the conditions of the test, and then we analyzed the game sequences, isolating the actions of the players with the ball and describing them in detail. Two main categories of actions are considered: favorable actions (F) and unfavorable actions (D). F-actions allow the attacking team (a) maintain possession, (b) to break the defense, or (c) to advance the ball into the end zone. D-actions imply (a) to risk possession of the ball, (b) to lose possession of the ball, or (c) to lose territory.

All F- and D-actions identified and categorized are simple actions (S). However, we also identified combined actions (C). C-actions are the addition of 2 or $3 \mathrm{~S}$-actions that, when happening consecutively, have a special tactical value, either positive (combined F actions CF-) or negative (combined D actions -CD-) (see Table 1).

\section{Coding protocols}

Game sequences were filmed to permit an observer to code all the simple actions performed by the ball carrier. In order to reduce the risk of misclassification, the observer was familiarized with the definitions in Table 1 before using the RAAI. Coding was carried out using a data collection sheet, which comprised two columns for each of the teams, and each action observed was added in the different rows along a game sequence.

\section{Measure of performance: the Index of Performance (IP)}

To obtain a measure of performance of the teams involved in the game we use the Index of Performance (IP). The IP is the score that results from the game assessment based 
“Assessing Novices' Game Performance in Rugby Union: The Rugby Attack Assessment Instrument (RAAI)”

by Llobet-Martí B, López-Ros V, Barrera-Gómez J, Joel Comino-Ruiz J

Journal of Teaching in Physical Education

(C) 2016 Human Kinetics, Inc.

on the aggregation of the actions of ball carriers observed in a game sequence. To calculate the IP, we assigned a positive or a negative weight to each of the possible $\mathrm{S}$ - and $\mathrm{C}$-actions. These weights were allocated according to the tactical relevance of every action. Thus, all Factions have a positive weight, and all D-actions have a negative weight (see Table 1).

The allocation criteria of weights was discussed and agreed with expert rugby coaches (see construct validity section). Criterion 1 establishes that all F-actions have a positive weight and all D-actions a negative weight. Criterion 2 determines that the weight of a CFaction always has to be higher than the sum of the weights of the simple F-actions (SF) involved in that $\mathrm{CF}$-action. In a similar way, the weight of a CD-action always has to be lower (i.e., more negative) than the sum of the weights of the simple D-actions (SD) involved in it. Criterion 3, about the actions weight value, states that the weights of the three CFactions coded results from the addition of the simple actions weights involved in a combined action plus an extra weight assigned according to the tactical value of each C-action. .

The IP is defined as the mean value of the weights associated to all the coded actions in the analyzed sequence and it can be calculated using the following formula:

$$
I P=\frac{\sum_{i=1}^{p} n_{i} \cdot w_{i}}{\sum_{i=1}^{p} n_{i}}=\frac{n_{1} \cdot w_{1}+n_{2} \cdot w_{2}+\cdots+n_{p} \cdot w_{p}}{n_{1}+n_{2}+\cdots+n_{p}},
$$

where $w_{1}, w_{2}, \ldots, w_{p}$ are all $\mathrm{p}$ possible different weight values, and $n_{1}, n_{2}, \ldots, n_{p}$ are the corresponding observed frequencies.

\section{Validity and reliability}

We assessed content and construct validity, and reliability. To assess content validity, a panel of four expert coaches, all of them involved in coaching a Spanish national side (one men's 7-a-side; two women's 15-a-side; and one under-19), revised the conditions of application, the definition of each action, and the weights allocation criteria. Firstly, they 
“Assessing Novices' Game Performance in Rugby Union: The Rugby Attack Assessment Instrument (RAAI)”

by Llobet-Martí B, López-Ros V, Barrera-Gómez J, Joel Comino-Ruiz J

Journal of Teaching in Physical Education

(C) 2016 Human Kinetics, Inc.

independently read the authors' proposal and were provided with some specific questions by the researchers (i.e. do you identify the actions proposed? do you propose changes to the criteria of weights allocation?) to which they gave suggestions for improvement. Secondly, the experts reached consensus on the most relevant identified actions of players and weights after discussing their previous feedback. One example of a feedback was the pertinence of including the fake pass as an action. The experts agreed that intentionality of this action could not be assessed and that its execution could not always be clearly observed, leading to its rejection. The final result obtained from this validity process has served to determine the units of analysis of the RAAI and the allocation of weights.

The construct validity was evaluated by comparing the IP scores corresponding to two trials. One of these trials was performed observing an under-12 inexperienced team (K1), and the other one observing a senior expert team (E1) that competes in the Spanish Premiership. The resulting IP scores were 0.141 and 1.916, respectively, and the difference between IP scores was significant (see Table 2).

Reliability was evaluated by testing the level of agreement between two different observers (inter observer reliability) and by the same observer in two different times (intra observer reliability), when analyzing data from the same situation (Agresti, 2013). We measured both agreements by using the weighted Cohen's kappa, which compares the classifications of the actions between the two observations. Weighted Cohen's kappa takes into account that the seriousness of disagreement depends on the difference between the weights of the actions to be compared (Agresti, 2013). To examine inter observer reliability of RAAI, two observers were trained (120 minutes) to analyze and code the actions of the players according to the criteria of analysis explained in this paper. The observers were both PE teachers. One of them had 16 years of experience and was a rugby coach and a former player. The other observer had 8 years of experience as a PE teacher, and was a former rugby 
“Assessing Novices' Game Performance in Rugby Union: The Rugby Attack Assessment Instrument (RAAI)”

by Llobet-Martí B, López-Ros V, Barrera-Gómez J, Joel Comino-Ruiz J

Journal of Teaching in Physical Education

(C) 2016 Human Kinetics, Inc.

player. At the time of the study, both were involved in coaching at different levels (under 21 and under 14). They classified the actions derived from the observation of six game sequences representing over $30 \%$ of the total time of one trial (N1). The resulting Cohen's weighted kappa was 0.979 . To assess intra observer reliability, one of the observers recoded the same six sequences one week later. When comparing the two classifications of this observer, the resulting Cohen's kappa was 0.972. The high values of Cohen's kappa obtained indicate a strong agreement (Kline, 2005). In relation to the test-retest reliability of the instrument, one observer applied the test to the same team two weeks apart (N1 and N2). The resulting IP scores were not significantly different, as shown in Table 2.

\section{Discussion and conclusions}

Firstly, our findings show that the IP is sensitive to the changes on the game performance of a group of novice players. Thus, the better a team plays, the higher its IP. Second, the IP is a score that takes into account the addition of individual players' actions in the game context as tactical skills. We agree with some studies that have emphasized that a tactical behavior is an action and, in this sense, mental solutions cannot be isolated from motor executions (e.g. Gréhaigne, Wallian et al., 2005). The IP intends to give to each action observed a tactical rate directly related to the solution of a tactical problem that arises from the game. Consequently, we consider the IP as a suitable score to assess tactical performance of players.

Finally, the RAAI introduces a team score instead of an individual one. The IP is understood as the result of the actions of the players involved in a game where cooperation is crucial. Therefore, a team score is the result of this teamwork. In this sense, Gréhaigne, Richard et al. (2005) suggest that in some cases the score attributed to a team as a whole may be useful to take into account specific behaviors of players during the game. 
“Assessing Novices' Game Performance in Rugby Union: The Rugby Attack Assessment Instrument (RAAI)” by Llobet-Martí B, López-Ros V, Barrera-Gómez J, Joel Comino-Ruiz J

Journal of Teaching in Physical Education

(C) 2016 Human Kinetics, Inc.

Gréhaigne, Wallian et al.'s (2005) idea of interwoven offensive and defensive matrices deployed in the rapport of strength of invasion games introduces one of the RAAI limitations and future perspectives. This aspect refers to the mutual offensive and defensive influence on the performance of a team and how it can be reflected on the results of the test. Another issue related to the use of this instrument is the weights allocation of actions in order to enhance the tactical value of simple and combined behaviors. It might be considered that these values are related to the system of play. However, we ponder whether the weights allocation is accurate enough in order to take into account this issue.

The RAAI has been developed in the context of a research which aim was to assess team performance along a learning sequence in an authentic learning environment. Its use in an educational setting is also plausible and promising. As an example, in the evaluation process, students could identify the actions with the whole group by viewing themselves playing, becoming active participants of this process (Gréhaigne, Richard et al., 2005).

The present study suggests that RAAI is a valid and reliable instrument to assess the performance of a team analyzing the actions of the ball carrier in a small-sided game of rugby union. The main contribution of the RAAI is that the qualification of the actions has been made previously with the allocation of weights according to the tactical relevance of the actions involved in the game. Another feature of the RAAI is its versatility; it may be used to assess the progress of a rugby team or used in PE lessons to assess the rugby performance of a group of students. However, the adaptation of the tool to other situations or games is not straightforward and would need a systematization process (Arias \& Castejón, 2012). Although a recent research shows very low repeatability of studies (Makel \& Plucker, 2014), we have constructed the IP in a way that provides objective measures of the RAAI, which favours replication, even in other contexts of educational research. Finally, in line with the conclusions of Arias-Estereo and Castejón's (2014) study, we provide an R package (R 
"Assessing Novices' Game Performance in Rugby Union: The Rugby Attack Assessment Instrument (RAAI)"

by Llobet-Martí B, López-Ros V, Barrera-Gómez J, Joel Comino-Ruiz J

Journal of Teaching in Physical Education

(C) 2016 Human Kinetics, Inc.

Foundation for Statistical Computing, Vienna, Austria), which computes the IP providing significance measures (confidence interval and p-value) when comparing two IP scores ${ }^{1}$.

\section{Acknowledgements}

We would like to thank Cristòfol Collado for his contributions to our study, and Andrea

Firth-Clark and Alexander T. Latinjak for their proof reading.

${ }^{1}$ This package, a user's guide, and a template file for storing the data needed for the IP calculations can be downloaded from http://www.mat.uab.cat/ jbarrera/IP.html. 
“Assessing Novices' Game Performance in Rugby Union: The Rugby Attack Assessment Instrument (RAAI)” by Llobet-Martí B, López-Ros V, Barrera-Gómez J, Joel Comino-Ruiz J

Journal of Teaching in Physical Education

(C) 2016 Human Kinetics, Inc.

\section{References}

Agresti, A. (2013). Categorical data analysis. Third edition. Hoboken (NJ): Wiley.

Arias, J.L., \& Castejón, F.J. (2012). Review of the instruments most frequently employed to assess tactics in physical education and youth sports. Journal of Teaching in Physical Education, 31, 381-391.

Arias-Estero, J.L., \& Castejón, F.J. (2014). Using instruments for tactical assessment in physical education and extra-curricular sports. European Physical Education Review, 20(4), 525-535. doi:10.1177/1356336X14539214

Biscombe, T. \& Drewett, P. (1998). Rugby: Steps to Success. Champaign, IL: Human Kinetics.

Bunker, D.J., \& Thorpe, R.D. (1982). A model for the teaching of games in secondary school. Bulletin of Physical Education, 18(1), 5-8.

Casey, A., \& Dyson, B. (2009). The implementation of models-based practice in physical education through action research. European Physical Education Review, 15, 175-199. doi:10.1177/1356336X09345222

Chen, W., Hendricks, K., \& Zhu, W. (2013). Development and validation of the Basketball Offensive Game Performance Instrument. Journal of Teaching in Physical Education, 32, 100-109.

Deleplace, R. (1979). Rugby de movement, rugby total. Paris: Editions EPS.

Den Duyn, N. (1997). Game sense - Developing thinking players workbook. Canberra, ACT: Australian Sports Commission.

Farias, C.F., Mesquita, I.R., \& Hastie, P.A. (2015) Game Performance and Understanding Within a Hybrid Sport Education Season. Journal of Teaching in Physical Education, in press. doi: http://dx.doi.org/10.1123/jtpe.2013-0149

Gabett, T., Wake, M., \& Abernethy, B. (2011). Use of dual-task methodology for skill assessment and development: Examples from rugby league. Journal of Sports Sciences, 29(1), 7-18. doi:10.1080/02640414.2010.514280

Gréhaigne, J.F., Godbout, P., \& Bouthier, D. (1997). Performance assessment in team sports. Journal of Teaching in Physical Education, 16, 500-516.

Gréhaigne, J.F., Richard, J.F., \& Griffin, L.L. (2005). Teaching and learning team sports and games. London: Routledge.

Gréhaigne, J.F., Wallian, N., \& Godbout, P. (2005). Tactical-decision learning model and students' practices. Physical Education and Sport Pedagogy, 10(3), 255-269.

doi:10.1080/17408980500340869 
“Assessing Novices' Game Performance in Rugby Union: The Rugby Attack Assessment Instrument (RAAI)" by Llobet-Martí B, López-Ros V, Barrera-Gómez J, Joel Comino-Ruiz J

Journal of Teaching in Physical Education

(C) 2016 Human Kinetics, Inc.

Griffin, L.L., Oslin, J.L., \& Mitchell, S.A. (1997). Teaching sports concepts and skills: A tactical games approach. Champaign, IL: Human Kinetics.

Harvey, S., Cushion, C.J., Wegis, H.M., \& Massa-Gonzalez, A.N. (2010). Teaching games for understanding in American high-school soccer: a quantitative data analysis using the game performance assessment instrument. Physical Education and Sport Pedagogy, 15(1), 29-54. doi:10.1080/17408980902729354

Hopper, T. (2003). Four Rs for tactical awareness: Applying game performance assessment in net/wall games. Teaching Elementary Physical Education. 14(2), 16-21

Kirk, D., \& MacPhail, A. (2002). Teaching games for understanding and situated learning: Rethinking the Bunker-Thorpe model. Journal of Teaching in Physical Education, 21, 177-192.

Kline, T.J.B. (2005). Psychological testing. A practical approach to design and evaluation. Thousand Oaks, CA: Sage Publications.

Mahlo, F. (1974). L'acte tactique en jeu. Paris: Vigot.

Makel, M. C., \& Plucker, J. A. (2014). Facts are more important than novelty replication in the education sciences. Educational Researcher, 43(6), 304-316. doi: 10.3102/0013189X14545513

Memmert, D. (2007). Can Creativity Be Improved by an Attention-Broadening Training Program? An Exploratory Study Focusing on Team Sports. Creativity Research Journal, 19(2-3), 281-291. doi:10.1080/10400410701397420

Memmert, D., \& Harvey, S. (2008). The Game Performance Assessment Instrument (GPAI): some concerns and solutions for further development. Journal of Teaching in Physical Education, 27, 220-240.

Miller, A. (2015). Games Centered Approaches in Teaching Children \& Adolescents: Systematic Review of Associated Student Outcomes. Journal of Teaching in Physical Education, 34, 36-58.

Nadeau, L., Richard, J.F., \& Godbout, P. (2008). The validity and reliability of a performance assessment procedure in ice hockey. Physical Education and Sport Pedagogy, 13(1), 65-83. doi:10.1080/17408980701444718

Oslin, J.L., Mitchell, S.A., \& Griffin, L.L. (1998). The Game Performance Assessment Instrument (GPAI): development and preliminary validation. Journal of Teaching in Physical Education, 17, 231-243.

Villepreux, P., Brochard, F., \& Jeandroz, M. (2007). Rugby: le jeu, les jouers, les entraîneurs. Evolution, apprentissage. Paris: Vigot. 
“Assessing Novices' Game Performance in Rugby Union: The Rugby Attack Assessment Instrument (RAAI)” by Llobet-Martí B, López-Ros V, Barrera-Gómez J, Joel Comino-Ruiz J

Journal of Teaching in Physical Education

(C) 2016 Human Kinetics, Inc.

Table 1: Simple and Combined Actions identified and Weights allocated to each action.

\begin{tabular}{|c|c|c|}
\hline Code & Description & Weight \\
\hline$c f_{1}$ & $\begin{array}{l}f_{3+2}: \text { Pass made and receiver breaks the defence without direct } \\
\text { opponent. }\end{array}$ & 8 \\
\hline$c f_{2}$ & $f_{3+1}:$ Pass made and receiver breaks the defence & 7 \\
\hline$c f_{3}$ & $f_{8+3+5}$ : Ball carrier is stopped, passes the ball and receiver can run & 5 \\
\hline$f_{1}$ & Ball carrier breaks the defense & 3 \\
\hline$f_{2}$ & Ball carrier breaks the defense without direct opponent & 3 \\
\hline$f_{3}$ & Ball carrier passes the ball & 2 \\
\hline$f_{4}$ & Breakdown (ruck or maul) without losing possession of the ball & 2 \\
\hline$f_{5}$ & Run with the ball in front or behind the defense & 1 \\
\hline$f_{6}$ & Picking up the ball from the floor & 1 \\
\hline$f_{7}$ & The action of starting the game & 1 \\
\hline$f_{8}$ & $\begin{array}{l}\text { Ball carrier is stopped or tackled without losing possession of the } \\
\text { ball }\end{array}$ & 1 \\
\hline$f_{9}$ & Ball carrier scores a try & 1 \\
\hline$f_{7}$ & The action of starting the game with a following D-action & 0 \\
\hline$f_{8}$ & Ball carrier is stopped or tackled with a following D-action & 0 \\
\hline$d_{1}$ & $\begin{array}{l}\text { The ball drops to the floor backwards without losing possession of } \\
\text { the ball }\end{array}$ & -1 \\
\hline$d_{2}$ & Ball goes out of the field & -1 \\
\hline$d_{3}$ & Ball carrier runs backwards & -1 \\
\hline$d_{4}$ & $\begin{array}{l}\text { Ball carrier's fault finishing the sequence without losing possession } \\
\text { of the ball }\end{array}$ & -2 \\
\hline$d_{5}$ & The ball drops to the floor backwards losing possession of the ball & -3 \\
\hline$d_{6}$ & Ball carrier's fault finishing the sequence losing possession of the ball & -3 \\
\hline$d_{7}$ & Ball carrier is stopped or tackled losing possession of the ball & -3 \\
\hline$d_{8}$ & Grouping (ruck or maul) losing possession of the ball & -3 \\
\hline$d_{9}$ & $\begin{array}{l}\text { Ball carrier's fault losing possession of the ball and continuing the } \\
\text { game }\end{array}$ & -4 \\
\hline$c d_{1}$ & $\begin{array}{l}f_{3+8}: \text { Pass made and the receiver is stopped without a chance of } \\
\text { running }\end{array}$ & -5 \\
\hline$c d_{2}$ & $\begin{array}{l}d_{3+7}: \text { Ball carrier runs backwards and is stopped or tackled losing } \\
\text { possession of the ball }\end{array}$ & -6 \\
\hline$c d_{3}$ & $\begin{array}{l}f_{3}+d_{7}: \text { Pass made and the receiver is stopped without a chance of } \\
\text { running and loses possession of the ball }\end{array}$ & -7 \\
\hline
\end{tabular}

${ }^{*} c f=$ combined favorable action; $f=$ favorable action; $d=$ unfavorable action; $c d=$ combined unfavorable action 
“Assessing Novices' Game Performance in Rugby Union: The Rugby Attack Assessment Instrument (RAAI)"

by Llobet-Martí B, López-Ros V, Barrera-Gómez J, Joel Comino-Ruiz J

Journal of Teaching in Physical Education

(C) 2016 Human Kinetics, Inc.

Table 2: Construct Validity and Test-retest Reliability results. In each case, IP scores and a $95 \%$ Confidence Interval are shown. In addition, the $p$-value for testing equal IP scores is shown.

\begin{tabular}{|c|c|c|}
\hline Construct Validity & IP & $\begin{array}{c}95 \% \text { Confidence } \\
\text { interval }\end{array}$ \\
\hline Trial K1 ${ }^{a}$ & 0.141 & $(-0.481,0.762)$ \\
\hline Trial E1 ${ }^{b}$ & 1.916 & $(1.455,2.377)$ \\
\hline \multicolumn{3}{|l|}{ value $<10^{-5}$} \\
\hline $\begin{array}{l}\text { Test-retest } \\
\text { Reliability } \\
\end{array}$ & IP & $\begin{array}{c}95 \% \text { Confidence } \\
\text { interval }\end{array}$ \\
\hline Trial N1c & 1.327 & $(0.964,1.690)$ \\
\hline Trial N2d & 1.282 & $(0.818,1.745)$ \\
\hline
\end{tabular}

$p$-value $=0.874$

a: trial of an under-12 team

b: trial of a senior expert team

c: first trial of an under-19 novice players team

$\mathrm{d}$ : second trial of the same (c) team two weeks later 